\title{
NEONATAL NECROTIZING ENTEROCOLITIS - A STUDY OF CLINICAL PROFILE AND OUTCOME
}

\author{
Patil Basavaraj ${ }^{1}$, Bhimalli Shivanand ${ }^{2}$, Nagarjuna Chadalavada ${ }^{3}$
}

${ }^{1}$ Associate Professor, Department of Paediatrics, M.R.M.C., Kalaburagi.

${ }^{2}$ Professor, Department of Paediatrics, M.R.M.C., Kalaburagi.

${ }^{3}$ Senior Resident, Department of Paediatrics, M.R.M.C., Kalaburagi.

\section{ABSTRACT}

\section{BACKGROUND}

Necrotizing Enterocolitis (NEC) is the most common life-threatening emergency of the gastrointestinal tract in the new-born period. The disease is characterised by various degrees of mucosal and transmucosal necrosis of the intestine. Necrotizing Enterocolitis (NEC) is primarily a disease of premature infants, although up to $10 \%$ of cases present in term and near-term babies.

\section{MATERIALS AND METHODS}

Neonates admitted to NICU's of Mahadevappa Rampure Medical College, Kalaburagi, from January 2014 - December 2015 were studied. Incidence of NEC was calculated based on total admissions in NICU. Clinical and laboratory evaluation of cases is done by features of NEC. CBC, Platelet count, CRP levels, ABG analysis, Serum Electrolyte levels, Stool for occult blood, X-ray, USG abdomen and Blood culture were done to assess the clinical profile and determine outcome according to Bell's staging.

\section{RESULTS}

Out of total 2155 admissions in NICU, 90 cases were diagnosed with NEC. Incidence of NEC in the study is $4.1 \%$. Prematurity is the most common risk factor. Antenatal risk factors were PIH and PROM in few cases. Preterms (77.7\%) were more affected than term babies (22.2\%). Increased number of term babies with NEC is due to sepsis and underlying predisposing factors. Mean age of onset of NEC in most of the cases was between 5 - 10 days; 62 (68.8\%) cases were in stage 1; 13 (14.4\%) cases were in stage 2 and 15 (16.6\%) cases were in stage 3. Commonest clinical features were elevated pregavage residuals (Gastric aspirates), stool for occult blood positivity, abdominal distension, lethargy and vomiting. Increased CRP titres and Thrombocytopenia were common laboratory findings. Severe cases presented with metabolic and respiratory acidosis, DIC and hyponatraemia. Causative organism in blood culture was Staph. aureus. All cases in stage 1 were improved. Mortality (22\%) is seen only in stage 2 and stage 3 of NEC. Average duration of hospital stay is 15 - 25 days.

\section{CONCLUSION}

In our study, incidence of NEC has considerably increased because of early diagnosis. Most affected babies were preterms. Increased number of term babies with NEC is due to sepsis and underlying predisposing factors. Bell's staging of the cases showed majority in stage 1 . All the cases in stage 1 were improved and discharged. Mortality was noted only in stage 2 and stage 3 cases.

\section{KEYWORDS}

Necrotizing Enterocolitis, Preterm, Stool for Occult Blood, Gastric Aspirates, Blood Culture, Sepsis, Thrombocytopenia.

HOW TO CITE THIS ARTICLE: Basavaraj P, Shivanand B, Chadalavada N. Neonatal Necrotizing enterocolitis - a study of clinical profile and outcome. J. Evolution Med. Dent. Sci. 2017;6(1):7-9, DOI: 10.14260/Jemds/2017/3

\section{BACKGROUND}

Necrotizing Enterocolitis (NEC) is primarily a disease of premature infants, although up to $10 \%$ of cases present in term and near-term babies.(1) The age at onset of NEC is inversely related to gestational age. Mean age at onset of NEC is 3 weeks for $<30$ weeks, 2 weeks for $31-33$ weeks, 5 days for $>34$ weeks and 2 days for full-term infants.

NEC is likely initiated with intestinal mucosal injury from any number of factors. Following this injury, bacteria in the gut proliferate with formula or breast milk as a substrate. The bacteria invade the damaged mucosa causing inflammation and ultimately necrosis of the infected area.(2)

Symptoms of NEC include vomiting, feeding intolerance, abdominal distension, blood in the stools, lethargy, apnoea

Financial or Other, Competing Interest: None.

Submission 12-12-2016, Peer Review 25-12-2016,

Acceptance 27-12-2016, Published 02-01-2017.

Corresponding Author:

Dr. Patil Basavaraj,

Associate Professor

Department of Paediatrics,

M. R. Medical College, Kalaburagi-585105.

E-mail: dr.basavarajpatil@gmail.com

DOI: $10.14260 /$ jemds $/ 2017 / 3$

(c) $\underset{\mathrm{BY}}{\mathrm{NC}} \mathrm{ND}$ and temperature instability. In severe cases, it evolves into progressive systemic shock with metabolic acidosis, hypotension and disseminated intravascular coagulation. Signs include abdominal distension, blood- or bile-stained emesis, bloody stools and pneumatosis intestinalis is the pathognomonic radiographic sign of the disease.(3)

Medical management is largely supportive. Although, the majority of NEC cases are treated medically, an estimated $20 \%$ to $40 \%$ of infants will require urgent surgical intervention including exploratory laparotomy, bowel resection and colostomy; however, mortality may approach $35 \%$ in these cases. $(4,5)$

\section{MATERIALS AND METHODS}

This prospective randomised, observational and interventional study was done in neonates admitted to NICU of Basaweshwar and Sangameshwar Hospital attached to Mahadevappa Rampure Medical College, Kalaburagi, during the period between January 2014 and December 2015. A total of 2155 cases were admitted to NICU and among them 90 cases were diagnosed with NEC.

Informed consent was taken. Clinical and laboratory evaluation was done in all cases and further classified according to Bell's staging. 
CBC, Platelet count, CRP levels, ABG analysis, Electrolyte levels, Stool for occult blood, x-ray, USG abdomen, blood culture were done in all cases. Clinical signs of suspected NEC (Stage 1) such as lethargy, vomiting gastric aspirates, stool for occult blood positivity were registered along with radiological signs like dilated bowel loops. Temperature instability and apnoeic episodes were not seen as Stage 1 cases. In severe NEC (Stage 2 and 3) apnoeic episodes, bradycardia, gross blood in stools, Thrombocytopenia, metabolic acidosis and hyponatremia were noted. Respiratory acidosis, shock and DIC were noted in Stage 3 NEC. Radiological signs like distended bowel loops, ascites and pneumatosis intestinalis were also noted. Pneumoperitoneum is noted only in Stage 3 cases. Management of the cases was carried out according to Bell's staging and outcome was analysed.

\section{RESULTS}

90 cases of NEC were reported in our hospital during the study period. Out of these, $52.2 \%$ were males and females were $46.7 \%$. Majority of the cases were delivered by vaginal delivery $(82.2 \%)$. Preterms were commonly affected $(77.7 \%)$. Late preterms were also included in the study. Term babies affected were $22 \%$. Increased incidence in term babies was due to sepsis, perinatal asphyxia, IUGR, hypoxia and packed cell transfusion for anaemia. In few cases CHD, exchange transfusion and polycythemia were risk factors.

Only $5.5 \%$ cases in the study were $<30$ wks. gestation. Majority were between $30-37$ wks. (72\%). Cases with $>37$ wks. gestation were $22.2 \%$.

Most of the babies were between 1 - $2 \mathrm{~kg}$ (58.8\%). Others were $>2 \mathrm{~kg}$ weight (41.1\%). In our study, there were no cases less than $1 \mathrm{~kg}$. Majority of the cases (58.8\%) had early onset NEC (< 5 days). In 33.3\% cases, NEC onset was between 5 10 days and $11 \%$ cases showed onset NEC $>10$ days.

Antenatal risk factors in the study were PIH (12.2\%) and PROM (2.2\%). Prematurity is the commonest predisposing factor followed by infections. Other risk factors were IUGR, perinatal asphyxia, CHD, exchange transfusion, packed cell transfusion.

Sepsis screening was positive in $85.5 \%$ cases. Most common causative organism isolated in blood culture was Staph. aureus (20\%). Others were Klebsiella, E. coli, pseudomonas and MRSA. No specific organism was identified in $56.6 \%$ cases.

In the present study, majority of cases were in Stage 1 $(68.8 \%)$ due to early diagnosis and appropriate intervention. Cases in Stage 2 and 3 were $14.4 \%$ and $16.6 \%$.

Most common clinical signs in stage 1 NEC were lethargy, vomiting, gastric aspirates, stool for occult blood positive, with mild ileus on radiological studies. Table 1 shows most common features and distribution of cases accordingly.

\begin{tabular}{|c|c|}
\hline $\begin{array}{l}\text { Systemic Intestinal and } \\
\text { Radiological Signs }\end{array}$ & $\begin{array}{c}\text { Cases in } \\
\text { Stage } 1 \text { NEC }(n=62)\end{array}$ \\
\hline Emesis & $28(45 \%)$ \\
\hline Lethargy and Poor Feeding & $25(43 \%)$ \\
\hline $\begin{array}{l}\text { Gastric Aspirates (Elevated } \\
\text { Pre-Gavage Residuals) }\end{array}$ & $56(90.3 \%)$ \\
\hline $\begin{array}{l}\text { Per Rectal Bleed (Stool for } \\
\text { Occult Blood Positive) }\end{array}$ & $53(85.4 \%)$ \\
\hline Normal x-ray \& USG & $30(48.3 \%)$ \\
\hline Mild Distended Bowel & $32(51.6 \%)$ \\
\hline \multicolumn{2}{|c|}{$\begin{array}{c}\text { Table 1. Distribution of Cases in Stage } 1 \text { NEC by Clinical } \\
\text { Presentation }\end{array}$} \\
\hline
\end{tabular}

In Stage 2 NEC ( $\mathrm{n}=13)$, all cases presented with Thrombocytopenia. Others were metabolic acidosis, tender abdomen with absent bowel sounds, pneumatosis intestinalis and minimal ascites. Stage 3 NEC $(n=15)$ cases, all presented with severe (or) profound Thrombocytopenia and packed cell transfusion was given for 7 (46.6\%) cases. Other features were hyponatremia, respiratory acidosis and shock with DIC. Pneumatosis intestinalis, pneumoperitoneum, definitive ascites were the characteristic radiological features. Table 2 shows features in severe NEC cases and distribution accordingly.

\begin{tabular}{|c|c|}
\hline $\begin{array}{l}\text { Systemic Intestinal and } \\
\text { Radiological Signs }\end{array}$ & $\begin{array}{c}\text { Cases in Stage } 2 \text { and } \\
3 \text { NEC }(n=28)\end{array}$ \\
\hline $\begin{array}{l}\text { Metabolic Acidosis } \\
(\text { Serum HCO3 < 20) }\end{array}$ & $10(35.7 \%)$ \\
\hline $\begin{array}{l}\text { Thrombocytopenia } \\
(<1,00,000 \mathrm{u} / \mathrm{L})\end{array}$ & $13(46.4 \%)$ \\
\hline $\begin{array}{l}\text { Severe Thrombocytopenia } \\
(<50,000 \mathrm{u} / \mathrm{L})\end{array}$ & $15(53.5 \%)$ \\
\hline $\begin{array}{l}\text { Respiratory Acidosis } \\
\text { (paCO2 }>45 \mathrm{mmHg})\end{array}$ & $2(7.1 \%)$ \\
\hline $\begin{array}{c}\text { Hyponatremia } \\
\text { (Serum } \mathrm{Na}+<130 \mathrm{mEq} / \mathrm{L})\end{array}$ & $4(14.2 \%)$ \\
\hline DIC & $10(35.7 \%)$ \\
\hline $\begin{array}{l}\text { Tender Abdomen with } \\
\text { Absent Bowel Sounds }\end{array}$ & $14(50 \%)$ \\
\hline Dilated Bowel Loops & $21(75 \%)$ \\
\hline Pneumatosis Intestinalis & $13(46.4 \%)$ \\
\hline Minimal Ascites & $5(17.8 \%)$ \\
\hline $\begin{array}{l}\text { Definite Ascites and } \\
\text { Pneumoperitoneum }\end{array}$ & $7(25 \%)$ \\
\hline \multicolumn{2}{|c|}{$\begin{array}{c}\text { Table 2. Distribution of Cases in Stage } 2 \text { and Stage } 3 \\
\text { NEC by Clinical Presentation }\end{array}$} \\
\hline
\end{tabular}

\section{Outcome in NEC}

Among the 90 cases studied $70(67.7 \%)$ cases have shown complete recovery. All cases in Stage 1 NEC were discharged on improvement of clinical signs and symptoms and there were no cases improved in Stage 3 NEC.

\begin{tabular}{|c|c|c|c|}
\hline Bell Staging & Stage 1 & Stage 2 & Stage 3 \\
\hline $\begin{array}{c}\text { Improved } \\
\text { and } \\
\text { Discharged }\end{array}$ & $62(100 \%)$ & $8(61.5 \%)$ & 0 \\
\hline Death & 0 & $5(38.4 \%)$ & $15(100 \%)$ \\
\hline Total & $\mathbf{6 2}$ & $\mathbf{1 3}$ & $\mathbf{1 5}$ \\
\hline \multicolumn{4}{|c|}{ Table 3. Outcome in NEC Cases as per Bell's Staging } \\
\hline
\end{tabular}

In preterms $72 \%$ cases improved and in term babies $90 \%$ cases were completely recovered. Majority cases expired were preterms $<34$ wks. gestation. Only $10 \%$ cases in term babies expired.

\begin{tabular}{|c|c|c|c|}
\hline $\begin{array}{c}\text { Gestational } \\
\text { Age }\end{array}$ & $\begin{array}{c}\text { Preterm } \\
\text { (<34 wks.) }\end{array}$ & $\begin{array}{c}\text { Late Preterm } \\
\text { (34 - 37 wks. })\end{array}$ & $\begin{array}{c}\text { Term } \\
\text { (> 37 wks.) }\end{array}$ \\
\hline Improved & 28 & 23 & 18 \\
\hline Death & 10 & 9 & 2 \\
\hline Total & $\mathbf{3 8}$ & $\mathbf{3 2}$ & $\mathbf{2 0}$ \\
\hline \multicolumn{3}{|c|}{ Table 4. Outcome in NEC Cases by Gestational Age }
\end{tabular}




\section{DISCUSSION}

Incidence of NEC in our study $(n=90)$ over a period of 2 years was similar to the study conducted in Chandigarh.(6) Higher incidence of NEC is noted in comparison to one reported study.(7) Males and females were equally affected in our study as similar to two studies in India.(6,7) Higher affection in males was reported in a study done in 28 preterms over a period of 6 months.(8)

Preterms were mostly affected in our study. Incidence in term babies has increased due to underlying risk factors. Similar reports were noted in two studies $(6,7)$ including both preterm and term babies. In one study, there were more preterms and less incidence in term babies.(9)

Most of the babies were between $1-2 \mathrm{~kg}$ in our study. Similar reports were in two epidemiological studies.(6,9) In babies with birth weight $>2 \mathrm{~kg}$ and $2.5 \mathrm{~kg}$, incidence of NEC was reported similar to the studies. In our study, there were no babies $<1 \mathrm{~kg}$ as noted in other studies.

Antenatal risk factors were PIH and PROM in our study. $\mathrm{PIH}$ is the risk factor in one study.(9) More number of cases with the same risk factors were noted in another study.(10)

Predisposing factors of NEC like prematurity and infections were noted in two studies(6,9); other study has hypoxia, infections, IUGR and CHD as the predisposing factors. (10)

Age of onset of NEC in our study is between 5 - 10 days. Similar results were noted in study over 42 neonates.(7) In another study,(6) early onset was reported in term babies (2 5 days) and late onset of NEC in preterms (10 - 15 days).

In our study, causative organism in blood culture was reported as staphylococcus aureus. In other studies,(6,7) most common reported was Klebsiella followed by E. coli and staphylococcus aureus.

Majority cases in our study were in Stage I as compared to two studies. In other studies, more cases were in Stage 2 and Stage 3 due to increased severity at presentation. $(6,9)$

Clinical presentation in our study showed that majority cases were stool for occult blood positive. Gastric aspirates were also seen in most of the included cases. Other features in Stage 1 were lethargy, vomiting mild ileus and normal $\mathrm{x}$ ray in few cases. Stage 2 and 3 cases presented with Thrombocytopenia, metabolic acidosis, bradycardia, apnoeic episodes, hyponatremia, DIC with shock. Only few cases had respiratory acidosis. Abdominal tenderness with absent bowel sounds were also noted in our study. Radiological features in Stage 2 and 3 were dilated bowel loops, pneumatosis intestinalis and ascites. Other studies have shown different presentations.

One study(9) showed more cases with lethargy, gastric aspirates and abdominal distension, Thrombocytopenia (< 100,000/mm3), metabolic acidosis. Radiologically, pneumatosis and pneumoperitoneum were seen. In another study(7) temperature instability, bradycardia, lethargy and vomiting were more common. Gastric aspirates and stool for occult blood positivity were more compared to our study. Abdominal distension, tenderness with absent bowel sounds and pneumoperitoneum were more common compared to our study.
Outcome of NEC in our study was similar to two reported studies.(6,7) Majority of cases in Stage 1 were improved and discharged. Mortality is noted in Stage 2 and 3 as reported. In few studies, mortality was reported in Stage 1 cases along with Stage 2 and 3 NEC.(11)

\section{CONCLUSION}

Our study showed significant increase in incidence of NEC among the babies admitted to NICU. Preterms were more affected as similar to other studies. Term babies were also significantly affected due to predisposing factors like IUGR, sepsis, asphyxia and packed cell transfusion. Majority of the cases in the study were improved due to early diagnosis and appropriate management according to Bellstaging. Mortality was seen in $22 \%$ cases due to severe disease.

\section{REFERENCES}

[1] Cloherty JP, Eichenwald EC, Stark AR. Manual of neonatal care. $6^{\text {th }}$ ed. Philadelphia: Lippincott Williams and Wilkins 2008:608-15.

[2] Sharma R, Hudak ML, Tepas JJ, et al. Impact of gestational age on the clinical presentations and surgical outcome of necrotizing enterocolitis. J Perinatolog 2006;26(6):342-7.

[3] Schnabl KL, Van Aerde JE, Thomson AB, et al. Necrotizing enterocolitis: a multifactorial disease with no cure. World J Gastroenterology 2008;14(14):2142-61.

[4] Abramo TJ, Evans JS, Kokomor FW, et al. Occult blood in stools and necrotizing enterocolitis. Is there a relationship? Am J Dis Child 1988;142(4):451-2.

[5] Gregory KE, DeForge CE, Kristan M, et al. Necrotizing enerocolitis in premature infants. Neonatal nutritional assessment, disease pathogenesis \& clinical presentation. Advances in Neonatal Care 2011;11(3):155-66.

[6] Narang A, Rao R, Bhakoo ON. Neonatal necrotizing enterocolitis-an epidemiological study. Indian Pediatr 1993;30(10):1207-14.

[7] Buch NA, Ahmad M, Ali SW, et al. Neonatal necrotizing enterocolitis: a clinical study and outcome. Department of neonatology \& critical care pediatrics SKIMS, Soura, Srinagar. JK-Practitioner 2001;8(4):237-9.

[8] Shah SSH, Saleem M, Mehmood T, et al. Frequency and outcome of necrotizing enterocolitis in preterm neonates. J Ayub Med Coll Abbottabad 2015;27(1).

[9] Mohammed LH, Khairy MA, Mohammed NR, et al. Retrospective study of necrotizing enterocolitis in neonatal intensive care unit of cairo university pediatric hospital. Med J Cairo Univ 2012;80(2):31-40.

[10] Olariu L, Olariu G, Ognean L. Necrotizing enterocolitis in preterm infant with gestational age $<32$ weeks,-incidence and risk factors. Jurnalul Pediatrului 2014;17:65-6.

[11] Buch NA, Ahmad SM, Ali SW, et al. An epidemiological study of neonatal necrotizing enterocolitis. Saudi Medical Journal 2001;22(3):231-7. 